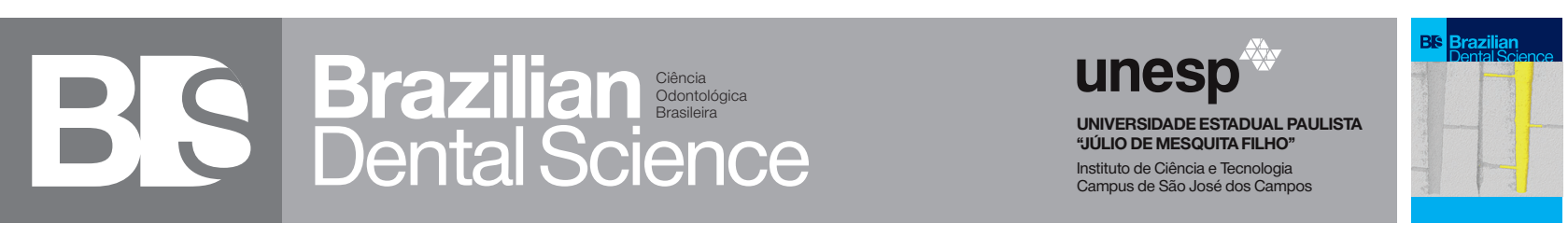

\title{
Effect of different impression methods and ceramic materials on adaptation of inlays
}

\author{
Efeito de diferentes métodos de moldagem e materiais cerâmicos na adaptação de inlays
}

Marília Pivetta RIPPE ${ }^{1}$, Elen GUERRA ${ }^{2}$, ArianneVallim Pinto COELHO ${ }^{2}$, Lilian Costa ANAMI ${ }^{2}$, Renata Marques de Melo MARINHO ${ }^{2}$, Marco Antonio BOTTINO ${ }^{2}$, Luiz Felipe VALANDRO ${ }^{1}$

1 - Federal University of Santa Maria - Prosthodontics Unit - Faculty of Odontology - Santa Maria - RS - Brazil.

2 - São Paulo State University (Unesp) - Institute of Science and Technology - São José dos Campos - Department of Dental Materials and Prosthodontics - São José dos Campos - SP - Brazil.

\section{ABSTRACT}

Objective: The aim of this study was to evaluate the internal and marginal adaptation of inlays fabricated from different types of impressions (conventional and digital) and different ceramics (feldspathic and lithium disilicate). Material and Methods: Forty premolars were prepared for all-ceramic inlay restoration and assigned to 4 groups $(n=10)$, according to the impression method (conventional with addition silicone and digital impression) and ceramic type (lithium disilicate and feldspathic ceramic blocks). For each type of impression, 10 inlays were milled from lithium disilicate blocks and the other 10 from feldspathic ceramic blocks in a CAD-CAM facility. The internal adaptation was analyzed by the replica technique. The marginal fit was analyzed under a stereo microscope by directly measuring the gap formed between the inlay and the tooth in the proximal and occlusal regions. Results: The marginal or internal adaptations were not affected by type of impression (conventional = digital impression), irrespective of the ceramic type. Only the internal adaptation was affected by the material type, i.e., feldspathic ceramic had lower values than lithium dissilicate ceramic, when considering the digital impression. Conclusion: The conventional and digital impressions promoted similar marginal and internal adaptation for feldspathic and disilicate ceramic inlays. For the digital impression the feldspathic inlays showed better internal adaptation than lithium dissilicate inlays .

\section{KEYWORDS}

Ceramics; Dental internal adaptation; Dental marginal adaptation; Dental impression technique.

\section{RESUIMO}

Objetivo: O objetivo deste estudo foi avaliar a adaptação interna e marginal de inlays confeccionadas a partir de diferentes tipos de moldagens (convencional e digital) e diferentes materiais cerâmicos (feldspática e dissilicato de lítio). Materiais e Métodos: Quarenta pré-molares foram preparados para inlay totalmente cerâmica e distribuídos em 4 grupos $(n=10)$ segundo o método de moldagem (convencional com silicone de adição e moldagem digital) e tipo cerâmica (dissilicato de lítio e blocos de cerâmica feldspática). Para cada tipo de moldagem, 10 inlays foram confeccionadas a partir de pastilhas de dissilicato de lítio e as outras 10 de blocos de cerâmica feldspática, por meio do sistema CAD-CAM. A adaptação interna foi analisada pela técnica da réplica. $\mathrm{O}$ ajuste marginal foi analisado com estéreo microscópio medindo diretamente o espaço entre a inlay e o dente nas regiões proximal e oclusal. Resultados: As adaptações marginais e internas não foram afetadas pelo tipo de moldagem (convencional = impressão digital), independentemente do tipo de cerâmica. Somente a adaptação interna foi afetada pelo material, sendo que a cerâmica feldspática apresentou menores valores que a cerâmica de dissilicato, considerando a moldagem digital. Conclusão: As moldagens convencional e digital promoveram adaptação marginal e interna semelhante de inlays de cerâmica feldspática e dissilicato testadas. Para moldagem digital, a cerâmica feldspática mostrou melhor adaptação interna do que a dissilicato de lítio.

\section{PALAVRAS-CHAVE}

Cerâmica; Adaptação interna dentária; Adaptação marginal dentária; Técnica de moldagem dentária. 


\section{INTRODUCTION}

$\mathrm{T}$ he preservation of healthy tooth structure should be always encouraged by using minimally invasive preparations, when possible, such as inlays and onlays. For maximum longevity of these restorations, the bond between the tooth structure and allceramic inlays should be reliable, since this type of restoration is retained in the preparation mainly by the bond between different substrates (dentin / enamel and restorative material) [1] and the low mechanical friction that takes place. [2] Thus, the ceramic type should be taken into account for a proper cementation. Both, feldspathic and lithium disilicate ceramic have shown to be suitable for inlay restorations.

In order to achieve greater longevity of inlay restorations, in addition to durable bond strength, the marginal accuracy is most important. $[3,4]$ Poor marginal fit increases the plaque retention sites and induces periodontal disease; [5] leads to microleakage of the oral cavity fluids, capable of resulting in endodontic inflammation [6] and secondary caries at restoration margins. [7] However, it is difficult to establish an acceptable marginal fit for inlay restorations, due to faults occurring during impression-taking and processing of the restorations. Furthermore the inherent limitations of adhesives should be considered, such as relatively high polymerization shrinkage; low resistance to degradation; and high thermal expansion coefficient. [8]

Therefore, good marginal adaptation is only possible if, firstly , a good impression is taken. The accuracy of the impression is critical to the success of the restoration. Nowadays, in addition to the conventional polyvinyl siloxane impression materials, digital impression can be used for clinical procedures: it is faster because it reduces the number of clinical steps and is more comfortable for the patient. In addition, the digital model can be sent to the lab by e-mail, without the need to fabricate a die and performing occlusal registration. [9]
As regards the accuracy of the impression type, Syrek et al. [10] and Pradíes et al. [11] showed that the digital impression promoted better marginal adaptation of allceramic crowns when compared with conventional two-step impression-taking. However, Almeida e Silva et al. [12] found no difference between the types of impressions. Moreover, Hamza et al. [13] showed that the type of ceramic might also influence the marginal adaptation of restorations. However, up to now no studies have compared the methods of conventional and digital impression of inlay preparations in terms of marginal and internal adaptation.

Therefore, the aim of this study was to evaluate the effect of the impression method (conventional or digital) and ceramic type (lithium disilicate and feldspathic) inlay restorations on the internal and marginal adaptation. The hypotheses were: 1) The method of impression would not influence the internal and marginal adaptation, irrespective of the ceramic material used; 2) The type of material would not influence the internal e marginal adaptation, irrespective of the method of impression.

\section{MATERIAL \& METHODS}

This study was approved by the Committee of Ethics in Research and the teeth were donated by the Human Teeth Bank.

Forty human maxillary premolars were selected, according to the inclusion criteria of no visible cracks or decay. The specimens were randomly assigned into four groups (http:// www.randomizer.org), according to table 1.

Table 1 - Experimental Design

\begin{tabular}{ccc|}
\hline Impressiontechnique & Material & Groups $(\mathbf{n = 1 0})$ \\
\hline \multirow{2}{*}{ Conventionalimpression } & Feldspathic & ConFel \\
& Disilicate & ConDis \\
\hline \multirow{2}{*}{ Digital impression } & Feldspathic & DigFel \\
& Disilicate & DigDis
\end{tabular}


The teeth were embedded in a cylinder ( $\mathrm{h}=14 \mathrm{~mm}, \varnothing=25 \mathrm{~mm}$ ) containing acrylic resin (Dencrilay, Dencril, Caieiras, Brazil) up to $3 \mathrm{~mm}$ below the cemento-enamel junction, with the occlusal surface parallel to the horizontal plane.

\section{Preparation}

Standardized cavity preparations (inlay type) were prepared in the teeth using a conical trunk diamond bur with rounded angles (KG Sorensen 3131, Barueri, Brazil). The burs were mounted in a high-speed hand piece fixed to a modified optical microscope. The preparation dimensions were as follows: buccal-lingual width, $3 \mathrm{~mm}$; occlusal box depth, $3 \mathrm{~mm}$; and rounded internal line angles. Each diamond bur was used for the preparation of five teeth. Afterwards, all preparations were polished with diamond burs with the same shape and lower grit (extra fine, KG Sorensen 3131FF).

\section{Impression methods}

- Conventional: Impressions of the cavities were taken with addition silicone and a onestep impression method (Elite HD, Regular Body, Zhermack, BadiaPolesine, Italy), and the impressions were poured using a type IV die stone (CAM-BASE type 4, Dentona, Dortmund, Germany), that had titanium based components in its composition to facilitate image obtaining of the preparation. The dies obtained from conventional impression were scanned with a laboratory scanner (inEos Blue, Sirona Dental Systems, Benshein, Hessen, Germany).

- Digital: The digital impressions were taken of the other half of the prepared teeth by using the intra-oral scanner CEREC AC Bluecam (Sirona Dental Systems). Before scanning, a titanium dioxide powder (Optispray, Sirona Dental Systems) was applied to the teeth. The powder particles create reference points on the smooth surfaces of teeth to facilitate scanning.

All the inlays were milled by the CEREC MC XL IN LAB (Sirona Dental Systems) from ceramic blocks made of feldspathic ceramic (VITABLOCS ${ }^{\circledR}$ Mark II - Vita Zahnfabrik, Germany) and lithium disilicate ceramic (Emax
CAD, Ivoclar-Vivadent,Schaan, Liechtenstein). Lithium disilicate inlays were sintered according to manufacturer's recommendation. The design of the inlays was standardized for all groups (space for the cement wasof $80 \mu \mathrm{m}$ ).

\section{Internal adaptation}

Internal adaptation was measured by using the replica technique. The tooth preparation was filled with a thin layer of light-body addition silicone (Elite, Zhermack), and the inlay was seated using a load of 750 g. After the impression material set, the inlay was removed, leaving a thin film of silicone adhering to the preparation, representing the space between the inlay and the tooth cavity. For the purpose of stabilization, a putty material was placed in the space previously occupied by the inlay, which adhered to the light-body film. With this procedure, the replica of the lightbody material could be removed. The replica was then cut mesio-distally, and one halfsection was used to measure the thickness at the pulpal wall. Each section was then cut into three parts, and the middle section was used to measure the thickness at the axial walls (Figure 1 ). The measurements were performed using stereomicroscopy (Discovery V20, Carl Zeiss, Gottingen, Germany). The average cement thickness of the pulpal and axial walls of each tooth was used in the statistical analysis.

\section{Marginal adaptation}

The restorations were "cemented" with small drop of light-body polyvinyl siloxane on the pulp wall in the prepared tooth cavity and a $750 \mathrm{~g}$ dead weight was applied only to the restoration by means of a stabilizing device so that the inlay would remain seated in the tooth, keeping the marginal zone free of impression material (without silicone's excesses). This procedure was performed in order to stabilize the inlay in the teeth for better analysis using stereomicroscopy (Discovery V20, Carl Zeiss, Gottingen, Germany). The fit was established by direct measurement of the marginal discrepancy between the inlay and the tooth structure. Seven points were measured in each 
region (mesial, distal and occlusal) as shown in Figure 1. The marginal fit value of the tooth was the average of all the measurements.

\section{Micromorphology of marginal integrity}

In order to assess the marginal integrity of the restorations after milling, the inlays were analyzedat 16 x magnification (JSM-6360, JEOL, Tokyo, Japan).

\section{Statistical analysis}

Shapiro-Wilk and Levene tests were carried out and showed data parametric and homogeneous respectively. The mean values of internal and marginal adaptation of the different impression methods (conventional Vs digital) for each ceramic material and the different materials (disilicate vs feldspathic) for each impression methods were subjected to two-way ANOVA and Tukey tests $(a=5 \%)$.

\section{RESULTS}

The marginal or internal adaptations were not affected by impression method (conventional $=$ digital impression), irrespective the inlay material (Table 2). Only the internal adaptation was affected by material: feldspathic had lower values that disilicate ceramic, when considering the digital impression.

Representative micrographs are shown in Figure 2. The marginal integrity after milling (Figure 2A,B) differed slightly, as the lithium disilicate seemed to have more irregular borders than the feldspathic ceramic.

Table 2 - Marginal and internal adaptation values $(\mu \mathrm{m})$

\begin{tabular}{ccccc}
$\begin{array}{c}\text { Impression- } \\
\text { methods }\end{array}$ & \multicolumn{2}{c}{$\begin{array}{c}\text { Mnternaladaptation } \\
\text { Material }\end{array}$} & \multicolumn{2}{c|}{$\begin{array}{c}\text { Marginal adaptation } \\
\text { Material }\end{array}$} \\
& Feldspathic & Disilicate & Feldspathic & Disilicate \\
Conventional & 190.93 & 206.59 & 167.96 & 173.64 \\
& $(66.84) \mathrm{Aa}$ & $(58.89) \mathrm{Aa}$ & $(103.22) \mathrm{Aa}$ & $(46.96) \mathrm{Aa}$ \\
\hline Digital & 147.24 & 212.22 & 140.52 & 170.28 \\
& $(44.38) \mathrm{Aa}$ & $(70.57) \mathrm{Ab}$ & $(26.08) \mathrm{Aa}$ & $(25.04) \mathrm{Aa}$
\end{tabular}

Different capital letters indicate a significant difference ( $p \ll 0.05)$ between the types of impression for feldspathic and disilicate ceramic (columns). Different small letters indicate a significant difference $(\mathrm{p}$ « 0.05$)$ between the types of materials for conventional and digital impressions (lines).

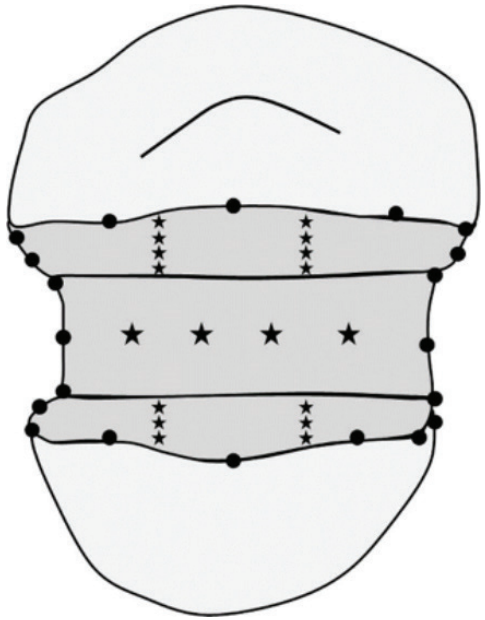

Figure 1 - Location of the points for fit measurements. The "stars" correspond to the internal adaptation and the "circles" to the marginal adaptation.

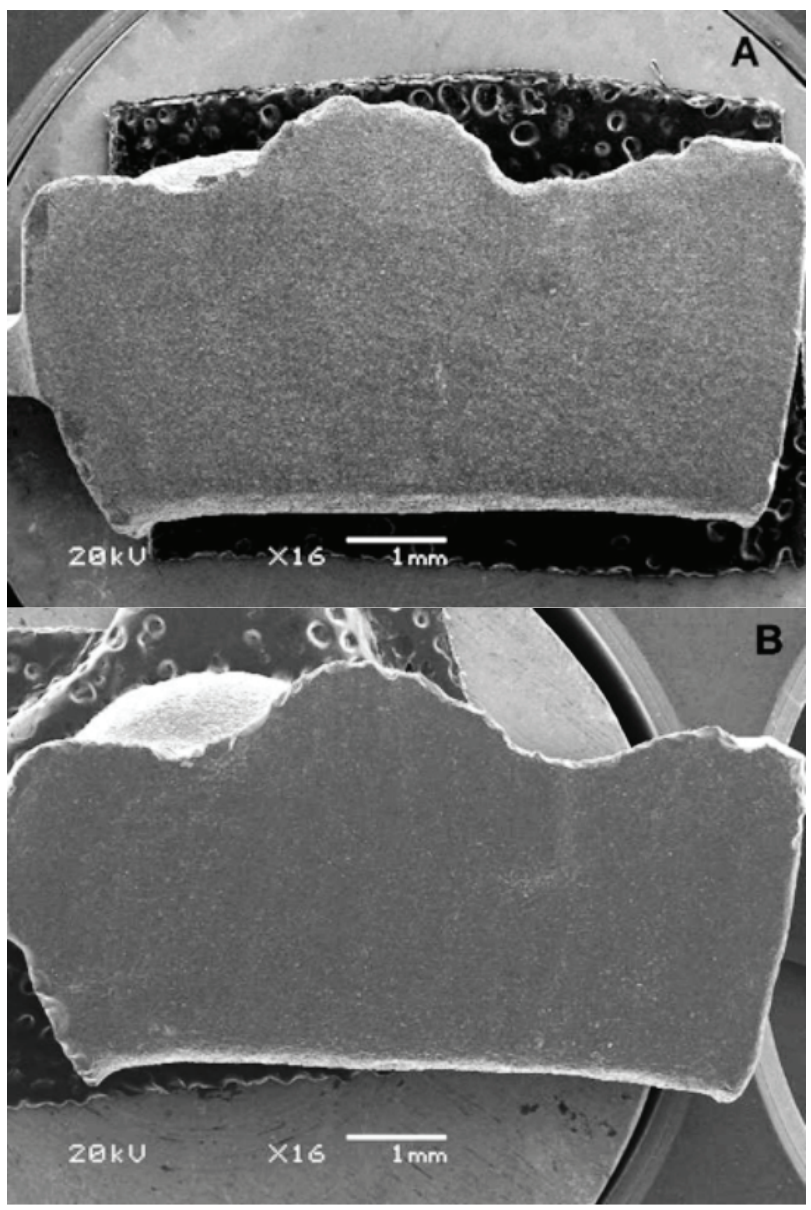

Figure 2 - Micrographs of the inlay margins after milling of feldspathic ceramic (A) and lithium disilicate ceramic (B). 


\section{DISCUSSION}

The first hypothesis of this study was accepted, since the type of impression did not affect the internal or the marginal adaptation. Those outcomes perhaps occurred due to the fact that the plaster models from the conventional impression were scanned with the laboratory scanner Ineos that capture the image using the same principle as the intra-oral scan BlueCam. These two scannerswork according to the principle of stripe light projection, combined with active triangulationthrough shortwavelength blue light .However, the master dies scanned by the Ineos, were poured using a special plaster containing titanium (CAM-BASE type 4, Dentona, Dortmund, Germany), which can be scanned by the optical camera without the need for any additional powder layer. On the other hand, the powder was used onthe teeth scanned with the CEREC AC Bluecam, which could negatively affect the crown adaptation to the prepared tooth. According to Schaefer et al. [14], the application of a coating powder had a detrimental effect on internal adaptation. Regarding the similar values for two impressions methods observed by us, we could perhaps consider that the 2 steps needed to conventional impression (inherent misfit the silicone and plaster) might been comparable with the possible negative effect of the powder layer applied on the teeth for the digital impression groups.

The second hypothesis of this study was partially accepted, since the type of ceramic influenced the internal adaptation inlays of the digitally impressed groups; however the marginal adaptation was not affected by the material. The feldspathic ceramic was better than disilicate in this case. The feldspathic and lithium disilicate ceramics were chosen for this study because of the difference in the composition of these materials. Lithium disilicate has a high elasticity modulus, around $95 \mathrm{GPa}$, while feldspathic ceramic has a modulus of $45 \mathrm{GPa}$. This high stiffness of the disilicate may hinder the milling, leading to its surface being more irregular, and decreasing its internal accuracy. This relationship between high modulus ceramic and less accuracy in the Cerec system has also been observed byHamza et al. [13] and Bottino et al. [15].

The literature is divergent about the thickness of the marginal gap considered clinically acceptable. According to Holmes et al. [16] a marginal gap 100 to $120 \mu \mathrm{m}$ is acceptable to avoid potential degradation or dissolution problems that could contribute to cement loss. However, other studies [17-19] have considered the marginal gap values of 100 to $200 \mu \mathrm{m}$ to be clinically acceptable for cemented restorations. Furthermore, in the present study, the cement thickness established in the CAM-CAM system was $80 \mu \mathrm{m}$. This space was recommended by the CEREC machine manufacturer (MC XL model, Sirona Dental Systems). Another important consideration is that the marginal gap measurement used in the present study was the absolute marginal discrepancy [20] that may provide higher values than that of the marginal gap.

With regard the method used to measure the restoration adaptation, replication of the space between a tooth and restoration, using a lightlbody silicone supported by a heavylbody silicone, is a recognized technique to evaluate the quality of a restoration and it is validated by the literature. According to Laurent et al. [21] the use of the replica with appropriate materials allows accurate prediction of the actual size of the in vivocement thickness after cementation, furthermore, this method can be used for measurement at the several location (cervical, axial or occlusal). According to Contrepois et al. [20], the main limitation of this technique is that it provides only a limited number of marginal gap measurements.

A limitation of this study was the use of only one type of digital impression, since there are several types of scanners operating at different capture principles to be evaluated. Thus, further studies should be conducted with other materials and types of digital impressiontaking, with different types of intra-oral scanners and different systems of inlay fabrications. 


\section{CONCLUSIONS}

Within the limitations of this study it concludes that the type of impression had no influence on the marginal and internal adaptation of feldspathic and disilicate ceramic inlays. For digital impression the feldspathic ceramic showed better internal adaptation than lithium disilicate.

\section{ACKNOWLEDGIMENTS}

The authors thank to Sirona - Brazil for the Cerec 3D Bluecam scanner (none conflict of interest).

\section{REFERENCES}

1. RHayashi M, Tsuchitani Y,Kawamura Y,Miura M, TakeshigeF,EbisuS Eight-year clinical evaluation offired ceramic inlays. Oper Dent. 2000 NovDec;25(6):473-81.

2. Missau T,Venturini AB, Pereira GKR, Prochnow C,Valandro LF, Rippe MP. Fatigue failure load of restored premolars: effect of etching the intaglio surface of ceramic inlays with hydrofluoric acid at different concentrations. Oper Dent. 2018 Mar-Apr;43(2):E81-E91.

3. Pera P,Gilodi S, Bassi F,Carossa S. In vitro marginal adaptationof alumina porcelain ceramic crowns.J ProsthetDent1994 Dec;72(6):585-90.

4. RinkeS, Huls A, Jahn L.Marginal accuracy and fracture strength of conventional and copy milled all-ceramic crowns. Int J Prosthodont 1995 JulAug;8(4):303-10.

5. Valderhaug J, Heloe LA. Oral hygiene in a group of supervised patients with fixed prostheses. J Periodontol. 1977 Apr;48(4):221-24.

6. Bindl A, Mormann WH.Marginal and internal fit of all-ceramic CAD/CAM crown-copings on chamfer preparations. J Oral Rehabil. 2005 Jun;32(6):441-7.

7. Kokubo Y,Ohkubo C, TsumitaM, Miyashita A, Vult von Steyern P,Fukushima S. Clinical marginal and internal gaps of Procera All Ceram crowns. J Oral Rehabil. 2005 Jul;32(7):526-30.

8. Schmalz G,Federlin M, ReichE. Effect of dimension of luting space and luting composite on marginal adaptation of a class II ceramic inlay. J Prosthet Dent. 1995 Apr;73(4):392-9.
9. Christensen GJ. Impressions are changing: deciding on conventional, digital or digital plus in-office milling. J Am DentAssoc. 20090ct;140(10):1301-4.

10. Syrek A, Reich G, RanfttD, Klein C, Cerny B, Brodesser J. Clinical evaluation of all-ceramic crowns fabricated from intraoral digital impressions based on the principle of active wavefront sampling. J Dent. 2010 Jul;38(7):553-9.

11. Pradíes G,ZarauzC,Valverde A, Ferreiroa A,Martínez-RusF.Clinical evaluation comparing the fit of all-ceramic crowns obtained from silicone and digital intraoral impressions based on wave front sampling technology. JDent. 2015 Feb;43(2):201-8.

12. Almeida e Silva JS, ErdeltK, EdelhoffD,Araújo É, Stimmelmayr M, Vieira LC, et al. Marginal and internal fit of four unitzirconia fixed dental prostheses based on digital and conventional impression techniques. Clin Oral Investig. 2014 Feb;18(2):515-23.

13. Hamza TA, Ezzat HA, El-Hossary MMK, Katamish HA, Shokry TE, Rosenstiel SF. Accuracy of ceramic restorations madewith two CAD/CAM systems. J ProsthetDent 2013Feb:109(2):83-7.

14. Schaefer0, Decker M, Wittstock F,Kuepper H, Guentsch A. Impact of digital impression techniques on the adaption of ceramic partial crowns in vitro. J Dent. 2014 Jun;42(6):677-83.

15. Bottino MA, CamposF, Ramos NC, Rippe MP, Valandro LF, Melo RM. Inlays Made From a Hybrid Material: Adaptation and Bond Strengths. Oper Dent. 2015 May-Jun;40(3):E83-91.

16. Holmes JR, Sulik WD, Holland GA, Bayne SC. Marginal fit of castable ceramic crowns. JProsthet Dent. 1992 May;67(5):594-9.

17. Boening KW, Wolf BH, Schmidt AE, Kästner K, Walter MH. Clinical fit of ProceraAllCeram crowns. JProsthet Dent. 2000 0ct:84(4):419-24.

18. Pelekanos S, Koumanou M, Koutayas SO,Zinelis S, Eliades G. Micro-CT evaluation of the marginal fit of different In-Ceram alumina copings. Eur $J$ Esthet Dent. 2009 Autumn;4(3):278-92

19. Mously HA, Finkelman M, Zandparsa R,Hirayama H. Marginal and internal adaptation of ceramic crown restorations fabricated with CAD/ CAM technology and the heat-press technique. J Prosthet Dent. 2014 Aug;112(2):249-56.

20. Contrepois M, Soenen A, Bartala M, Laviole 0 . Marginal adaptation of ceramic crowns: A systematic review. JProsthetDent. 2013 Dec;110(6):447-54.

21. Laurent M, Scheer P,Dejou J, Laborde G. Clinical evaluation of the marginal fit of cast crowns - validation of the silicone replica method. J Oral Rehabil. 2008 Feb;35(2):116-22.

\section{Luiz Felipe Valandro} (Corresponding address)

Federal University of Santa Maria

Faculty of Odontology

Head of Ph.D.-M.Sci.D. Graduate Program in Oral Science

Prosthodontics-Biomaterials Unit

R. Floriano Peixoto, 1184, 97015-372,

Rio Grande do Sul State, Santa Maria, Brazil.

Date submitted: 2018 Feb 14

E-mail: lfvalandro@hotmail.com
Accept submission: 2018 Jul 17 